\title{
FENOLOGIA DA GRAVIOLEIRA (Annona muricata) EM ÁREA DE CERRADO DO AMAPÁ, BRASIL.
}

\author{
Tânia Brito do NASCIMENTO'; Aderaldo B. GAZEL FILHO²; \\ Jackson de A. dos SANTOS ${ }^{3}$
}

RESUMO - O trabalho teve como objetivo avaliar a fenologia de graviola (Annona muricata L.) cultivada em área de cerrado do Amapá. Foram escolhidas quatro plantas, ao acaso, de seis progênies de graviola, da coleção do Campo Experimental do Cerrado, no Centro de Pesquisa Agroflorestal do Amapá (CPAF-Embrapa). As progênies avaliadas foram a graviola A, graviola B, FAO II, Morada, Lisa e plantas oriundas da matriz 415 (M-415) da coleçào do Centro de Pesquisa Agroflorestal da Amazônia Oriental (CPATU-Embrapa). O clima é do tipo Ami e o solo é um Latossolo Amarelo arenoso distrófico. Foram observadas queda de folhas em todas as progênies de graviola após a safra (maio a julho) e na seca estacional (setembro a outubro). A floração ocorreu durante o periodo chuvoso, com picos em fevereiro e julho. A produção anual de flores foi superior na graviola B (115) e FAO II (97). A frutificação foi expressiva de dezembro a março. O vingamento de frutos sobressaiu-se na graviola A $(9 \%)$ e FAO II $(6,7 \%)$. O pico da colheita foi no mês de março, exceto para a graviola A que foi em maio.

Palavras-chave: cerrado, queda foliar, floração, frutificação, colheita.

Phenology of Soursop (Annona muricata) in the Savanna of Amapá State, Brazil.

ABSTRACT - This study evaluated the phenology of soursop (Annona muricata L.) cultivated in a savanna area. Four trees were randomly chosen from each of six cultivars of the Embrapa Amapá experimental collection in a savanna ecosystem. The cultivars were: soursop A, soursop B, FAO II, Morada, Lisa and M-415 of Embrapa Amazonia Oriental. The climate type is Ami and the soil is classified as a Typic Haplorthox. Leaf fall happened in all soursop cultivars in May and June (after harvest) and September and October (dry season). Flowering occurred during the rainy season, with extremes in February and July. Annual flower prodution was superior in soursop B (115) and FAO II (97). Fruit development was expressive from December to March. Fruit set stood out on soursop A ( $9 \%)$ and FAO II $(6,7 \%)$. Peak of the fruit harvest was in March, except for soursop A which was in May.

Key-words: savanna, leaf fall, flowering, fruiting, harvest.

\section{Introdução}

Apesar da gravioleira (Annona muricata L.) ser conhecida há bastante tempo, adaptada à região e explorada comercialmente, é ainda pouco estudada do ponto de vista agronômico, principalmente quanto à fenologia. Esses conhecimentos permitem explicar muitas reações das plantas ao ambiente, sendo fundamentais para o desenvolvimento da cultura, auxiliando na identificação de variedades de gravioleiras portadoras das características de planta e de fruto agronômica e

\footnotetext{
${ }^{1}$ Pesquisador/Bolsista DCR-CNPq, Centro de Pesquisa Agroflorestal do Amapá/ CPAFEMBRAPA. Cx. postal 10, 68902-280, Macapá-AP. jksantos@osite.com.br

${ }^{2}$ Pesquisador, Centro de Pesquisa Agroflorestal do Amapá/CPAF-EMBRAPA. Cx. postal 10, 68902-280, Macapá-AP. agazel@cpafap.embrapa.br

${ }^{3}$ Eng . Agrônomo, Centro de Pesquisa Agroflorestal da Amazônia Ocidental/CPAA-EMBRAPA. Cx. Postal 319, 69011-970, Manaus-AM.
} 
comercialmente desejáveis.

No tocante à mudança foliar na gravioleira, Freitas (1997) verificou pico de queda de folhas em gravioleira em junho, imediatamente após a colheita na região de Visconde do Rio Branco-MG e atribuiu a ocorrência às temperaturas relativamente baixas. Falcão et al. (1982) registraram queda foliar intensa na gravioleira durante o pico de safra entre janeiro e março em Manaus-AM.

A floração de gravioleira ocorre durante a maior parte do ano (Figueroa, 1978; Freitas, 1997). Pinto \& Genú (1984) citaram a ocorrência de antese a partir de novembro, em Planaltina-DF, enquanto Freitas (1997) observou floração entre outubro e janeiro, em Visconde do Rio BrancoMG. Falcão et al. (1982) registraram floração durante todo o ano em Manaus-AM, com picos entre setembro e janeiro, e afirmaram não existir um padrão definido de floração para a espécie na região.

Durante o florescimento, a gravioleira necessita de um período de estiagem (Saavedra, 1977; Calzavara \& Müller, 1987; Ramos, 1992), a fim de favorecer a fecundação das flores e formação dos frutos, uma vez que a presença de chuvas nessa fase provoca o abortamento das flores e frutos. Cavalcante (1976), Figueroa (1978) e Falcão et al. (1982) afirmam ser continua a frutificação da gravioleira.

$O$ vingamento de frutos na graviola encontrado por Falcão et al. (1982) foi de $40 \%$, enquanto que nas condições de cerrado em Brasília, Pinto \& Silva (1994) observaram vingamento de $53,4 \%$ para a graviola A, $23,8 \%$ para a graviola B, $22 \%$ para Morada, 21\% para Blanca e $10,2 \%$ para FAO II, cultivares pertencentes a um banco de germoplasma do Centro de Pesquisa Agropecuária do Cerrado - CPAC/EMBRAPA, sendo que a graviola Morada e Blanca são de origem colombiana. $\mathrm{O}$ baixo vingamento de frutos está relacionado com o fenômeno da dicogamia protogínica, em que a maturação do gineceu ocorre antes da maturação do androceu; com a heterostilia, posição do gineceu acima do androceu; e com a escassez de insetos polizadores, os quais constituem-se em barreiras à polinização e fertilização (Manica et al., 1994; Pinto \& Silva, 1994).

Araque (1967) observou grande variação entre plantas quanto a capacidade de produzir frutos. Figueroa (1978) observou que a produção é contínua na gravioleira, pois apresenta frutos de todos os tamanhos no decorrer do ano, resultando em diferentes colheitas durante $\mathrm{o}$ ano, porém com picos marcantes, influenciados pelas condições climáticas da região de cultivo. Falcão et al. (1982) registraram maior frutificação no período de janeiro a março, correspondente ao periodo chuvoso em região tropical, Pinto \& Genú (1984) verificaram que a colheita concentrou-se de abril a maio (clima tropical), e Freitas (1997) registrou colheita em maio (clima tropical de altitude).

Este estudo teve como objetivo avaliar a fenologia de seis cultivares de graviola introduzidas no estado do Amapá, constituintes de um banco de germoplasma cultivado em área de cerrado. 


\section{Material e Métodos}

Foram escolhidas, ao acaso, quatro plantas de cada cultivar de graviola (seis), totalizando 24 plantas, com idade de sete anos, pertencentes a uma coleção do Campo Experimental do Cerrado, do Centro de Pesquisa Agroflorestal do Amapá (CPAFEmbrapa). As cultivares avaliadas foram: graviola A, graviola B, FAO II, Morada, Lisa e M-415, sendo a última oriunda da coleção do Centro de Pesquisa Agroflorestal da Amazônia Oriental (CPATU-Embrapa), e as demais do Centro de Pesquisa Agropecuária do Cerrado - CPAC/ EMBRAPA, cultivadas em monocultivo, no espaçamento de $7 \times 7 \mathrm{~m}$.

O clima é do tipo Ami, segundo a classificação de Köppen, com temperatura média anual em torno de $27^{\circ} \mathrm{C}$, umidade relativa do ar média anual de $88 \%$ e precipitação pluviométrica anual de $2.500 \mathrm{~mm}$, com período de estiagem de agosto a dezembro. O solo é um Latossolo Amarelo arenoso distrófico.

As avaliações foram realizadas semanalmente, no período de fevereiro/97 a janeiro/98, sendo que as quatro observações semanais foram agregadas e analisadas como uma única observação mensal. Para as observações de queda foliar fez-se um coroamento abrangendo toda a projeção da copa. Semanalmente, varria-se a área, as folhas eram separadas e avaliadas.

Com relação à floração, utilizouse o mesmo método da queda foliar. Após a antese, sucede-se a senescência e as pétalas caem ao chão, a cada três pétalas externas encontradas registrou- se uma flor. Como a senescência das flores ocorre, aproximadamente, seis semanas após o seu lançamento (Escobar et al., 1986; Worrell et al., 1994; Freitas, 1997), este tempo foi conferido retroativamente à data da observação, para registrar o dia do aparecimento da gema floral.

Durante a frutificação, os frutilhos que surgiram foram marcados com fitas plásticas em toda a planta, no estádio "escova". Quando estes amadureciam e caiam ao chão eram colhidos e registrados, a fim de verificar o período de colheita.

\section{Resultados e Discussão Mudança foliar}

Verificou-se queda foliar durante todo o ano (Tab. 1), porém até abril o montante de folhas perdidas mantevese baixo e praticamente constante. No entanto, a partir da segunda quinzena de maio, a queda foliar aumentou consideravelmente, com pico em junho, caracterizando uma mudança parcial de folhas após o periodo de safra. Freitas (1997) também verificou pico de queda foliar na mesma época e após a colheita, e atribuiu a perda de folhas à ocorrência de temperaturas relativamente baixas na região de Visconde do Rio Branco-MG. O período de queda foliar registrado não coincide com o de Falcão et al. (1992), que ocorreu durante o pico de safra entre janeiro e março. A exceção foi a graviola B, que evidenciou queda acentuada a partir de junho.

No caso específico da primeira troca de folhas do ano, verificou-se que simultaneamente à queda ocorreu 
o lançamento de folhas novas, sendo que no início de agosto as plantas já tinham a folhagem restabelecida. A troca de folhas se estendeu por aproximadamente três meses em todas as plantas, indicando uma característica intrínseca da espécie, a qual não elimina de uma só vez suas folhas, fazendo-a de forma gradual.

Entre outubro e novembro ocorreu outra troca de folhas, provavelmente em decorrência da ausência de chuvas (Fig. 1B) em setembro e outubro (seca estacional). Antes de sua queda as folhas perderam a coloração de verde intenso, passando para verde-pálido ou verde-amarelado. As plantas ficaram quase desfolhadas, sendo que as folhas novas só apareceram na segunda quinzena de dezembro, em resposta ao recomeço das chuvas em novembro. A gravioleira revela, em condições de cerrado, uma considerável sensibilidade ao estresse hídrico prolongado. O tipo Lisa perdeu quantidades menores de folhas em relação aos demais, e iniciou a queda foliar no final de outubro, mais tardiamente.

\section{Floração}

A floração se estendeu por todo o período de observação (Fig. 2), apenas em diferentes intensidades, como ocorre nas observações de Figueroa (1978), Falcão et al. (1982) e Freitas (1997). A média anual de flores entre as cultivares variou de 62,6 a 115 flores. A graviola $\mathrm{B}$ e FAO II destacaram-se quanto a produção anual de flores, com 115 e 97 flores, respectivamente, seguidas da graviola A e M-415. Verificou-se que todas as cultivares reagiram da mesma forma aos estímulos climáticos, mostrando comportamentos de floração semelhantes em todo o período, ao contrário de Falcão et al. (1982) que afirmaram não haver um padrão de floração na região de Manaus, apesar da estiagem que ocorre.

A floração concentrou-se em dois períodos, de janeiro a março e de

Tabela 1. Mudança foliar de seis cultivares de graviola durante os meses de fevereiro/97 a janeiro/98 no cerrado do Amapá. CPAF-EMBRAPA, Macapá-AP, 1997.

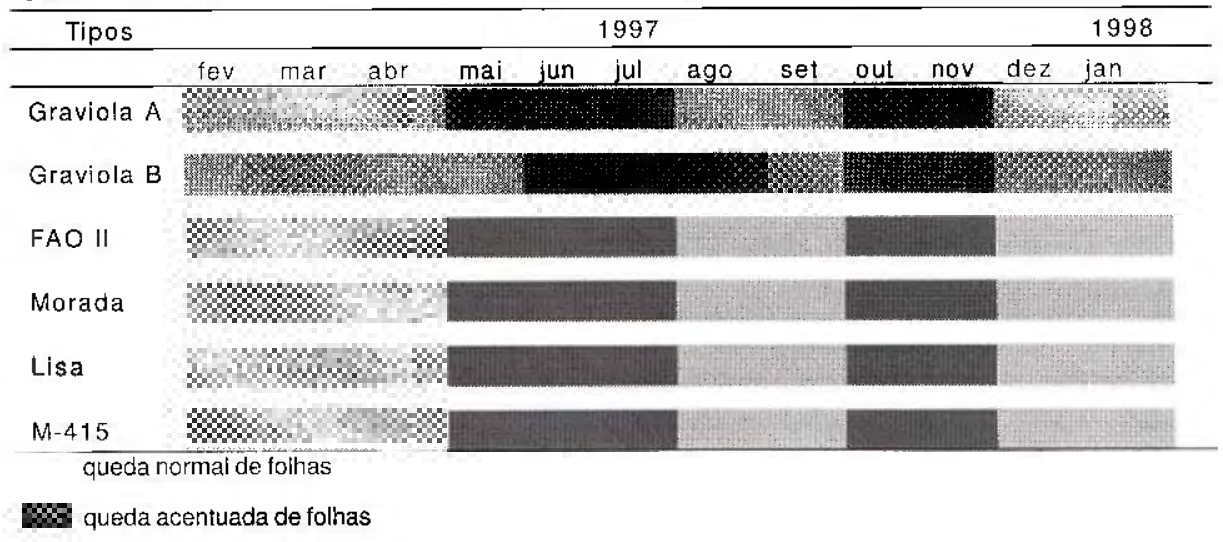


A

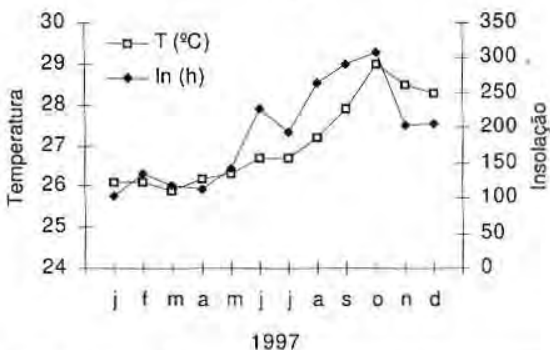

B

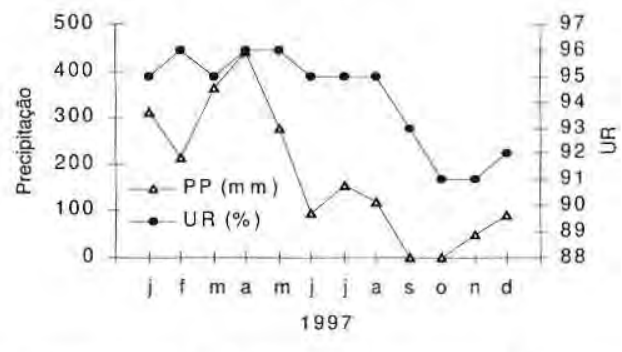

Figura 1. Dados meteorológicos do Campo Experimental do Cerrado do Centro de Pesquisa Agroflorestal do Amapá-CPAF/EMBRAPA, no período de janeiro a dezembro/97. ATemperatura T $\left({ }^{\circ} \mathrm{C}\right)$ e Insolação IN (h); B- Precipitação PP $(\mathrm{mm})$ e Umidade relativa UR (\%).

maio a julho, com picos em fevereiro e julho, respectivamente. As épocas de floração citadas por Falcão et al. (1982), Pinto \& Genú (1984) e Freitas (1997) não condizem com as mencionadas aqui, mas todas coincidem com períodos chuvosos, o que distingue a época de floração de uma região para outra. Apesar da precipitação constante durante o período de floração (Fig. 1), nota-se que todas as cultivares mostraram significante floração no período.

No período de fevereiro a abril, devido a elevada ocorrência de chuvas, o montante de flores registradas foi consideravelmente menor com relação ao período de maior floração (maio a julho), cuja precipitação havia diminuído e a temperatura e insolação aumentado. A interação desses fatores parece ter atuado na indução do florescimento. Embora o excesso de chuvas diminua a floração, ficou caracterizado que na gravioleira a floração é marcante no primeiro semestre do ano, que corresponde ao período chuvoso. Nos meses de setembro, outubro e novembro, o número de flores chegou a niveis baixissimos em relação ao restante do período, provavelmente como conseqüência da escassez de chuvas na época.

\section{Frutificação}

A frutificação expressiva se deu no período de dezembro a março para todas as cultivares (Fig. 3). O melhor vingamento de frutos foi verificado na graviola A $(9 \%)$, concordando com Pinto \& Silva (1994), seguida da FAO II $(6,7 \%), M-415(4,5 \%)$ e Morada (1\%). A graviola A apresentou vingamento de frutos ao longo do ano. Em contrapartida, a Lisa produziu uma quantidade muito pequena de frutos, quase desprezivel. A frutificação (Fig. 3) foi expressiva em meses de baixa precipitação (Fig. 1), concordando com Saavedra (1977), Calzavara \& Müller (1987) e Ramos (1992). Verificou-se uma baixa produção de frutos nos meses de maio e junho, correspondente a baixa produção de flores nos meses de março e abril, que deram origem a estes frutos. A quantidade muito pequena de frutos 
Graviola A

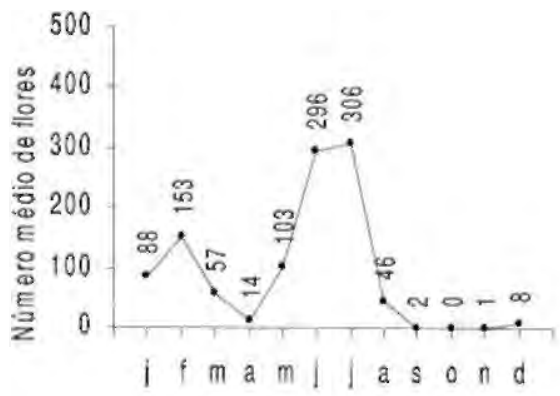

1997

FAO II

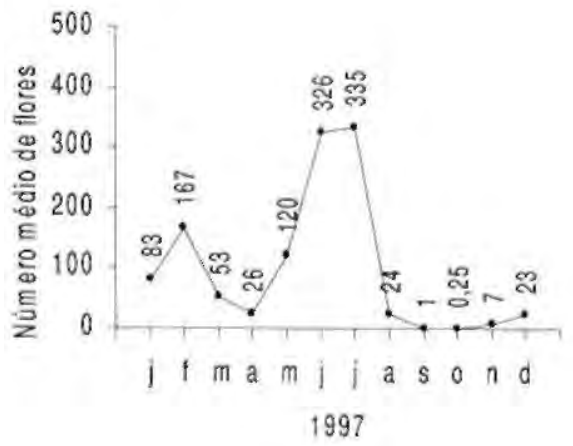

Lisa

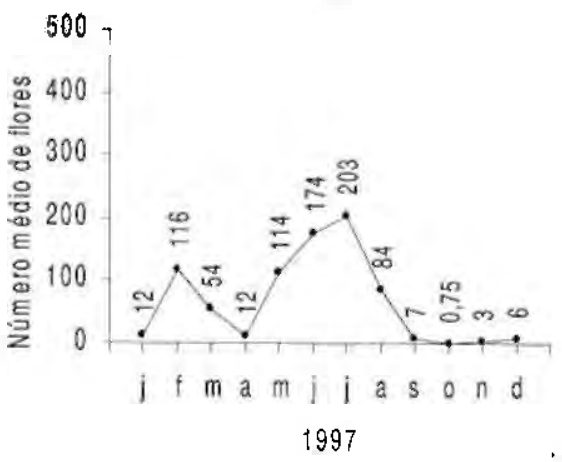

Graviola B

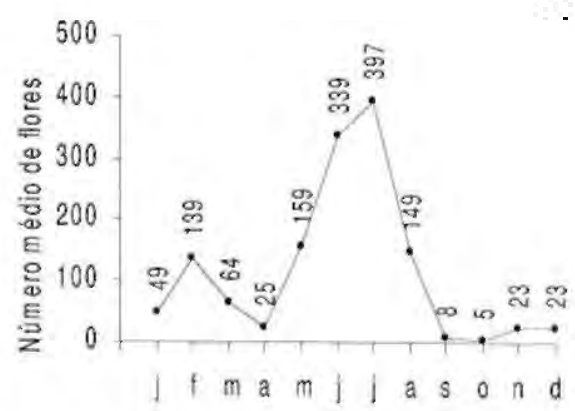

1997

\section{Morada}

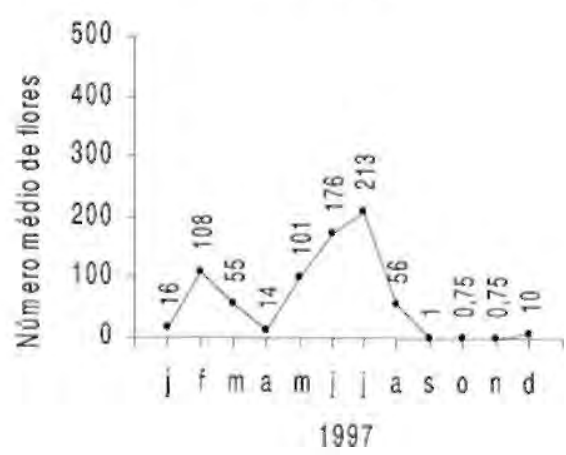

M-415

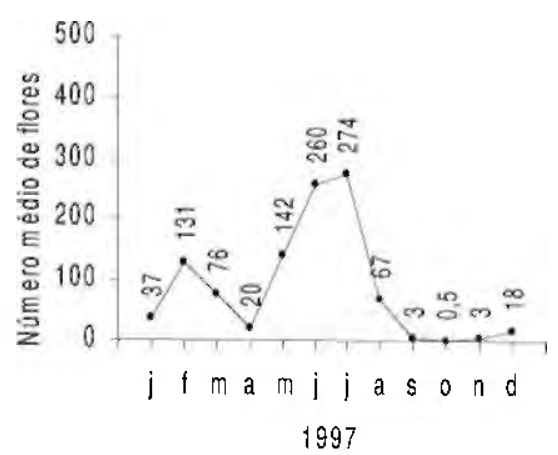

Figura 2. Distribuição da floração e produção média de flores de seis cultivares de graviola no cerrado do Amapá, durante os meses de janeiro a dezembro de 1997. CPAFEMBRAPA, Macapá-AP, 1997. 
Graviola A

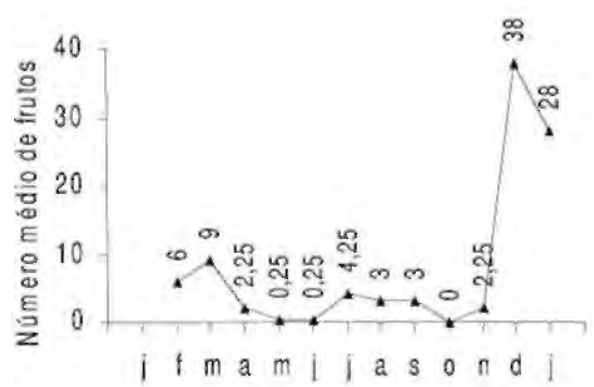

1997

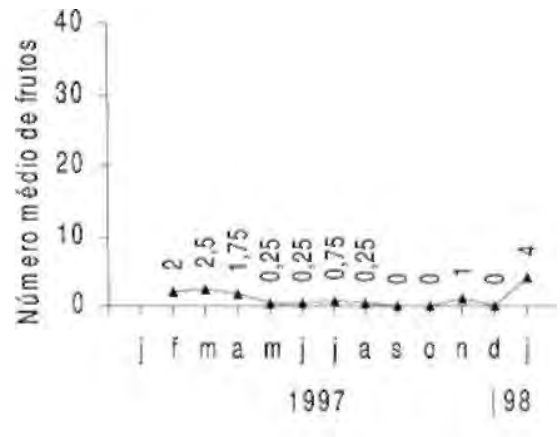

FAO I
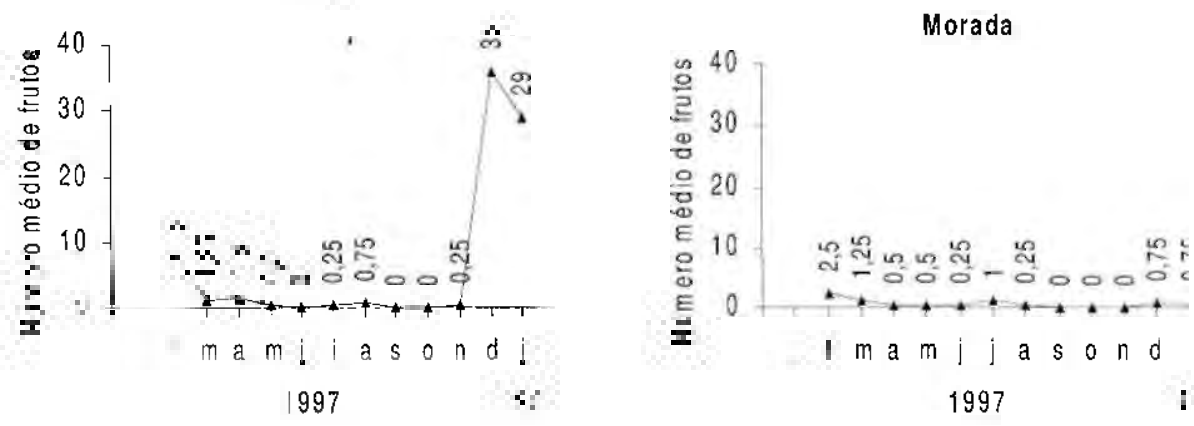

Lisa
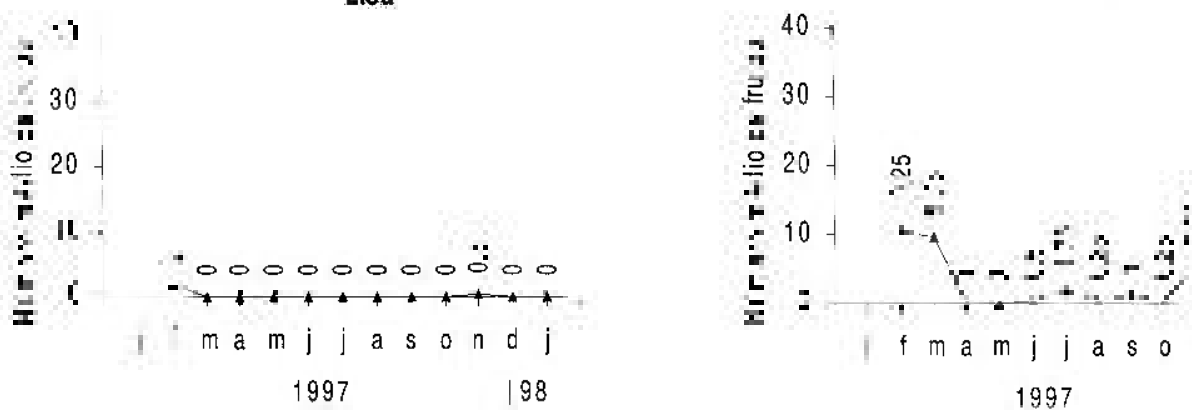

Figura 3. Frutificação de seis cultivares de graviola no cerrado do Amapá, durante os meses de fevereiro/97 a janeiro/98. CPAF-EMBRAPA, Macapá-AP, 1997. 
vingados em relação ao número de flores foi verificada em todas as cultivares.

O aparecimento de frutos maduros ocorreu a partir de março para todas as cultivares, com exceção da Lisa. A graviola A e M-415 destacaram-se em produção (Fig. 4), a qual foi distribuida por períodos amplos durante $o$ ano. A colheita teve seu pico no mês de março, sendo que para a graviola $\mathrm{A}$ foi em maio. No mês de novembro somente a M-415 apresentou frutos maduros, sendo que a ausência de frutos nesse período foi atribuída ao aborto dos frutos que ocorreu na estiagem de outubro a novembro (Fig. 1).

Os períodos de colheita evidenciaram que as cultivares não seguem o mesmo padrão, com variações consideráveis tanto em relação a época de produção quanto ao número de frutos, confirmando os relatos de Araque (1967). A variação na época de colheita está certamente relacionada a fatores climáticos locais, especialmente o regime hidrico (Falcão et al., 1982) e a diferença genética entre as cultivares (Freitas, 1997).

$\mathrm{O}$ número de frutos maduros (Fig. 4) em relação ao de frutos vingados (Fig. 3) foi baixo. A presença das pragas como a broca-do-fruto (Cerconota anonella) e cochonilha (Pinnaspis sp.), e de doenças, principalmente antracnose, também relatadas por Pinto \& Silva (1994), Junqueira et al. (1996), Livera \& Guerra (1996), foram alguns dos fatores mais importantes na perda de frutos antes da maturação, sendo observados por todo o periodo de avaliação.

\section{Conclusões}

A floração e frutificação da gravioleira em condições de cerrado, ocorreu durante quase todo o ano. A resposta aos estimulos climáticos foi semelhante para as cultivares em geral com relação à floração e queda foliar. A floração coincidiu com períodos chuvosos. O vingamento de frutos foi expressivo nos meses de menor precipitação, com destaque para a graviola A e FAO II. O periodo de colheita variou bastante entre as cultivares. A graviola A e M-415 destacaram-se por colheitas em períodos mais longos.

\section{Bibliografia citada}

Araque, R. 1967. La guanabana. Série Cultivos, 13, Consejo del Bienstar Rural, Caracas 16p.

Calzavara, B.B.G.; Müller, C.H. 1987. Fruteira tropical: a gravioleira (Annona muricata L.). Documentos, 47. EMBRAPA-CPATU, Belém.

Cavalcante, P.B. 1976. Frutas comestiveis da Amazônia. I. Publicações avulsas, 17, Museu Paraense Emílio Goeldi, Belém.

Escobar, W.T.; Zarate, R.D.; Bastidas, A. 1986. A biologia floral y polinizacion artificial del guanabana, Annona muricata L., em condiciones del Valle del Cauca, Colombia. Acta Agronomia, 36(1):7-20.

Falcão, M.A.; Lleras, E.; Leite, A.M.C. 1982. Aspectos fenológicos, ecológicos e de produtividade da graviola (Annona muricata L.) na região de Manaus. Acta Amazonica, 12(1):27-32.

Figueroa, M. 1978. El cultivo de la guanabana. Trabalho apresentado no I Curso Internacional sobre Fruticultura 


\section{Graviola A}

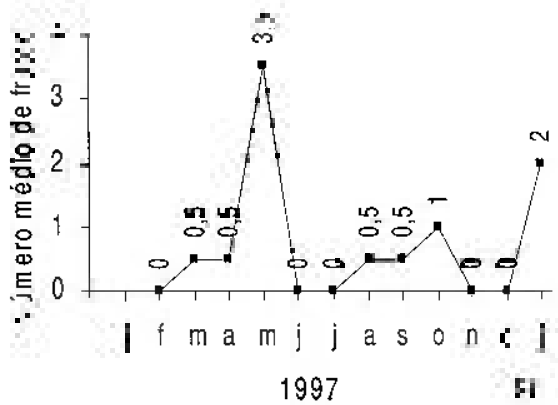

FAO I
Graviola B

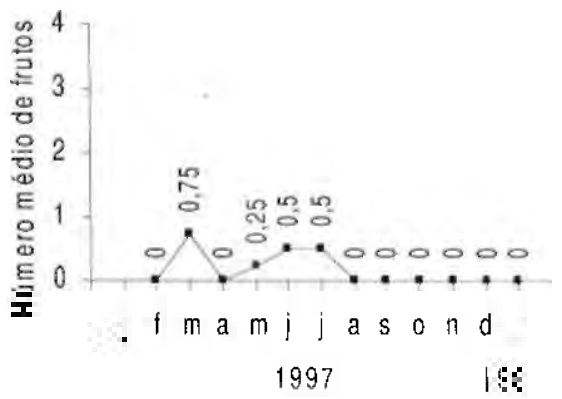

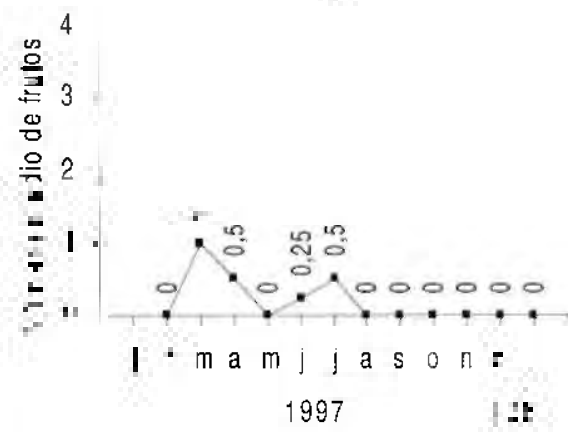

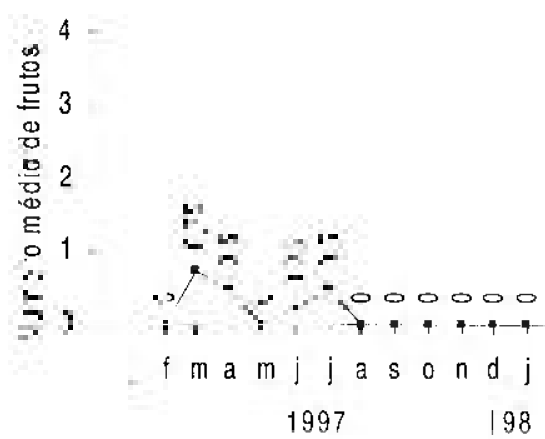

Lisa
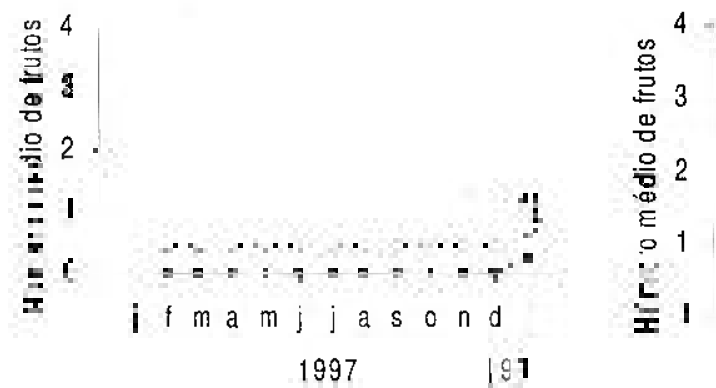

$M \cdot 415$

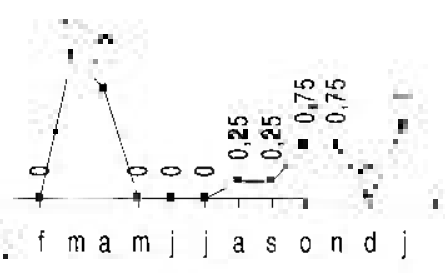

1997

198

Figura 4. Periodos de colheita e média de frutos colhidos de scis cultivares de graviola no cerrado do Amapá, durante os meses de fevereiro/97 a janeiro/98. CPAF- EMBRAPA, Macapá-AP, 1997. 
Tropical, Maracaya, Venezuela, 29/10 a 14/11/78. 32p.

Freitas, G.B. 1997. Propagação, florescimento, frutificação e produção da gravioleira (Annona muricata L.). Tese de Doutorado em Fitotecnia, Universidade Federal de Viçosa, Viçosa, 87p,

Junqueira, N.T.V.; Cunha, M.M.; Oliveira, M.A.S.; Pinto, A.C.Q. 1996. Graviola para exportação: aspectos fitossanitários. MAARA-FRUPEX, Brasília. 41p.

Livera, A.V.S.; Guerra, N.B. 1996. Desenvolvimento físico da graviola. Revista Brasileira de Fruticultura, 18(2): 225-233.

Manica, I.; Accorsi, M.R.; Belloto, F.A.; Fioravanço, J.C.; Gama, F.; Kist, H.G.K.; Morales, C.F.; Paiva, M.C.; Schwar, Z.F.S. 1994. Cultivo de Anonáceas: atacherimolia-graviola. Evangraf, Porto Alegre, 116p.

Pinto, A.C.; Genú, P.J.C. 1984. Contribuição ao estudo técnico-científico da graviola (Annona muricata L.). Anais, VII Congresso Brasileiro de Fruticultura. Sociedade Brasileira de Fruticultura/ EMPASC, Florianópolis, 2: 529-546.

Pinto, A.C.Q.; Silva, E.M. 1994. Graviola para exportação: aspectos técnicos da produção. MAARA-FRUPEX, Brasília. 41p.

Ramos, V.H.V. 1992. Cultura da gravioleira (Annona muricata L.). In: Donadio, L.C.; Martins, A.B.G.; Valente, J.P. (Eds.). Fruticultura tropical. FUNEP, FCAV/ UNESP, Jaboticabal. p. 127-157.

Saavedra, E. 1977. Influence of pollen grain stage at the time of hand pollination as a factor on fruit set of cherimoya. Hortscience, 12(2):117-118.

Worrell, D.B.; Carrington, C.M.S.; Huber, D.J. 1994. Growth, maturation and ripening of soursop (Annona muricata L.) fruit. Scientia Horticuturae, 57:7-15.

\section{Aceito para publicação em 10/04/2002}

